\title{
The Future of Female Genital Cutting: An Evolution of its Medicalization
}

\author{
Tammary Esho
}

\section{$1 \quad$ Introduction}

Some time back I was part of a conversation sparked by reports of an increase in the medicalization of female genital cutting (FGC $)^{1}$ in Kenya. Countries at the forefront of this practice include Egypt, Nigeria, Sudan and Kenya (Shell-Duncan et al. 2016). The rise in its medicalization seems to be based on the demand and supply of these services within the practising communities. The demand is driven by educated, wealthy women and families from FGC practising communities in Kenya and abroad, and the supply by healthcare providers (HCPs) attracted by the high prices paid for their specialized services. An increase in the demand for female genital cosmetic surgery (FGCS), or clitoral reconstruction, by specialized surgeons was among the concerns voiced. The purpose of this chapter is to stimulate discussion on the similarities between FGC and FGCS and to demonstrate how support for FGCS may influence efforts to curb FGC.

The conversation was along the following lines. A female friend commented that she had "visited the plastic surgeon's clinic the other day ... and guess what! The women walking into the clinic for consultation looked so sophisticated - they seemed like they had just landed from Dubai!" To this a male friend retorted, "You know what, I guess this plastic surgeon makes a ton of money from his services ... actually his clients are composed of the Who's Who in Kenya and within the region."

FGC is a form of violence involving the partial or total removal of parts of the female external genitalia, or other injury to those parts, for non-medical reasons (WHO 2018). In practising communities, it is generally associated with social norms that define acceptable behaviour and that are governed by a set of known sanctions or a powerful process of internalization. The custom serves to coerce women into upholding norms that perpetuate gender inequalities and that undercut their right to bodily integrity. The practice is upheld by many ethnic communities in Africa, the Middle East, Asia, parts of Latin America

1 In the present-day discourse, FGC is also known as female genital mutilation (FGM), but for reasons of consistency, I have opted to standardize on the more 'neutral' term, FGC.

(C) TAMMARY ESHO, 2022 | DOI:10.1163/9789004471641_029

This is an open access chapter distributed under the terms of the CC BY-NC 4.0 License. 
and throughout the world's diasporic communities. Globally, more than 200 million girls and women live with FGC in 30 countries, mostly in Africa and the Middle East; as many as three million girls are at risk of being cut every year (Gruenbaum 2015; Shell-Duncan et al. 2018). The trends mentioned in the recent UNICEF (2O2O) report have now been overshadowed by the ongoing global COVID-19 pandemic. Indeed, according to the UNFPA (2020), the pandemic has exacerbated the risk to women and girls, with an additional two million FGC cases projected to occur over the next decade that could otherwise have been averted. The pandemic threatens to widen gender inequalities: anecdotal evidence suggests that more girls are being exposed to FGC due to the CoviD-19 lockdown measures, including the closure of schools and the loss of livelihoods. This has placed more strain on families, and often forced them into agreeing to a marriage because of the bride-price (Chai 2020). Research is now suggesting that COVID-19 has increased FGC and early forced marriages in some communities in Kenya (Amref 2020a).

Despite decades of campaigns in various parts of the world, FGC remains a global problem and affects many women in diasporic communities. It is a human rights violation that deprives women and girls of their right to health. Despite a slight overall decline in its prevalence, however, population growth exposes ever more young girls to it (UNICEF 2016). Various multipronged approaches have sometimes worked (Shell-Duncan et al. 2016) and successful interventions have been found to trigger change from within communities. For example, a community-led initiative by the Maasai of Kajiado County, Kenya, has brought about a 24.2 per cent decline in its prevalence over the past ten years (Amref 2020b).

In this chapter, I express my increasing concern that the evolving trend towards medicalizing FGC will undermine the campaign to end the practice. This is because its medicalization seems to introduce a false assurance that if medical specialists perform the operation, there are likely to be fewer complications, and thus fewer grounds for objecting to the practice.

There are several reasons for the growing medicalization of FGC (Doucet et al. 2017). First, it is an unintended consequence of the campaign to end FGC using the public health risk as a strategy - the practising communities merely respond by medicalizing the procedure to reduce the health risks to their daughters. Second, many HCPs within the practising communities have the same social values, so thus act in the spirit of 'helping' the girls who will be subjected to the practice anyway. Cultural obligations are invoked to overlook their professional commitment to 'do no harm'. HCP s often claim to feel torn between such values and upholding their medical code of ethics. Third, in line with the conversation at the start of this chapter, the more specialized 
medical surgeons are taking over the procedures previous performed by lower tiers of HCP s. Among the reasons cited are the associated economic benefits: some Kenyan private clinics charge as much as US $\$ 4000$ for these specialist services, which of course only the wealthier members of society can afford.

\section{Therapeutic versus Non-Therapeutic Female Genital Modifications: Convergence of FGC and Female Genital Cosmetic Surgeries}

In some FGC practising countries, HCP s (mostly nurses and midwives in Sudan, medical doctors in Egypt, and a combination of various health professionals in Kenya) are taking over from the traditional cutters (UNFPA-UNICEF 2017). There is, however, resentment. On the one hand, these HCP s are not trained to perform FGC, while on the other it contravenes their medical oath to 'do no harm'. As a result, the gaps created by this double criticism end up being filled by trained plastic surgeons performing female genital cosmetic surgery (FGCS) and claiming medical grounds for the procedure. These specialists also provide corrective procedures. Though intended to repair the damage caused by FGC, I argue that this practice may result in its perpetuation: girls and women may decide to comply with social norms and undergo the cut with a view to getting the FGC 'corrected' in later life, with those who can afford it perhaps opting for clitoral reconstructive surgery after FGC. Personal communication with these clients suggests that they see it as a corrective procedure of a personal nature after having ensured community acceptance. In some instances, these interlocutors confided, this 'correction' took place in secret, behind their husband's or family's back.

It is clear that this evolution may slow the process of abandoning FGC. Yet, the hypothesis that the rising trend of corrective surgeries after FGC correlates with an increasing prevalence of the latter, needs to be further researched. Another hypothesis in need of further empirical scrutiny is that the incidence of (medicalized) FGC is increasing under the guise of FGCS, as clients and HCP S exploit the gaps in the legal framework that gives provision for medical reasons that may necessitate FGCS.

These issues remain a matter of concern. The emergence of these new practices points to shortcomings in existing legal policies and frameworks; by permitting certain forms of genital modifications it derails the progress achieved by the campaigns to end FGC and by the prohibitions enshrined in law. For instance, in Kenya's case the 2011 Prohibition of FGC Act and other legal frameworks define FGC as all procedures involving the partial or total removal of the female genitalia or any other injury to the female genital organs, or any harmful procedure to the female genitalia for non-medical reasons. These 
include (a) clitoridectomy, which is the partial or total removal of the clitoris or the prepuce; (b) excision, which is the partial or total removal of the clitoris and the labia minora, with or without excision of the labia majora; (c) infibulation, which is the narrowing of the vaginal orifice with the creation of a covering seal by cutting and juxtaposing the labia minora or the labia majora, with or without excision of the clitoris (National Council for Law Reporting 2011). These definitions could, arguably, also apply to procedures such as clitorolabiaplasty. However, the act states that a sexual reassignment procedure or a medical procedure that has genuine therapeutic purpose for the patient (and, hence, according to the wHO, guarantees her physical, mental and social wellbeing) falls outside its scope (Grad 2002).

This definition therefore leaves out similar procedures (such as FGCS) that are (claimed to be) conducted for medical reasons. At the same time though it is imperative to highlight the similarity regarding adult women's demands for FGC and FGCS: are both responding to cultural notions of what are considered 'normal' and 'desirable' external female genital organs? A recent guide for general practitioners performing FGCS claims that no concomitant rise in the incidence of congenital or acquired disease conditions warrant this surgery. Rather, it appears that the rising demand is a response to changing cultural norms (Australian Society for Plastic Surgeons 2015). The guide posits that this surgery is increasingly being sought by women who want to feel 'normal' or look 'desirable' (Bramwell et al. 2007). As a result, general practitioners are increasingly receiving requests from patients seeking surgery due to concerns about the appearance of their genitalia (Liao and Creighton 2011).

The UN calls for a zero-tolerance approach and condemns all forms of genital cutting as harmful and degrading to women; it infringes on their rights to health and physical integrity (UNFPA 2014). However, the zero-tolerance approach only applies to traditional and customary forms of genital cutting, not to cosmetic alterations of the female external genitalia (O'Neill et al. 2020). Considering the amount of genital tissue removed in both FGC and FGCS, the two procedures are essentially the same. Anatomically, there is little to distinguish FGC from many of the FGCS procedures such as clitoro-labiaplasty (Ostrzenski 2012). What does differ is why, how, where and by whom it is done: while FGC is known to take place in unsterile environments, FGCS takes place in a clinical setting whereby sterility is ensured.

Argument over what are 'normal' or 'desirable' female genitalia unearth those on woman's autonomy and freedom of choice. HCP s assume that a patient 
asking for FGCS is exploiting her freedom of choice, and will claim health reasons as medical justification. The emphasis on female autonomy over whether or not to opt for FGCS, however, promotes individualism and pushes up the demand for medicalized FGC. This is demonstrated by the following two cases from Kenya.

\subsection{The Court Case}

In 2017, a medical doctor filed a case with the Kenya High Court against the Prohibition of FGC Act 2011 (National Council for Law Reporting 2011). She called for the following (the details of this court case may not be discussed exhaustively as it is ongoing):

- that Prohibition of the Female Genital Mutilation Act 2011 be abolished;

- that the Anti-FGC Board (a board that oversees anti-FGC work in Kenya) be disbanded;

- that women above the age of 18 years have the right to choose and consent to female circumcision;

- that the procedure be medicalized so that adult women may be allowed to have it in a 'safe' way;

- she also argues that female circumcision is a cultural right and that it does not have any negative health or sexual repercussions for women.

In essence, the petitioner seeks to promote women's rights and freedoms as enshrined in the constitution. According to her, at stake is the right to culture and, more specifically, a woman's right to make her own choice whether or not to undergo FGC. As a matter of public importance - the fight against female genital mutilation occupies a large part of Kenya's national discourse - this case gives us a glimpse into what the future of $\mathrm{FGC}$ will look like when the argument around woman's autonomy and freedom of choice is used as a benchmark to advocate for FGC in the guise of FGCS (see Bhalla 2018). Obviously, these are weighty issues, especially because they affect the rights of girls and women who carry the heaviest health burden. The determination of this petition will set a precedent on the balance between cultural practices, rights and individual freedoms (National Council for Law Reporting 2017) that, however, may jeopardize the progress made over the last decades, a steady decline of FGC in many communities.

\section{2}

\section{The Cutting of Adult Women among the Kipsigis Community}

A second case is situated among the Kalenjin, Kipsigis ethnic group in Mauche, Nakuru County. Here a growing number of adult women, mostly educated and married with children, 'choose' to undergo FGC. Data from this community show that this trend emerged after the post-election violence of $2007 / 8$ and 
the subsequent civil strife between the Kalenjin and their neighbouring political rivals (Esho et al. 2017).

The Kalenjin embraced and benefited from the 'education of the girl child initiative' introduced in the 198 os by Daniel Arap Moi, the second president of Kenya, who himself hailed from this community. The social norm among the Kalenjin was to cut girls during their teenage years, but because of this initiative many of them averted FGC while pursuing their education, as evidenced by its reduced prevalence in the community (KNBS 2015).

In December 2013, it was reported in the news that several adult women had been admitted to the then Nakuru Provincial General Hospital with complications following botched FGC procedures (Macharia 2013) carried out by a traditional cutter. Though the women claimed that they 'chose' to undergo FGC, our data show that their husbands and mothers-in-law had put pressure on them to agree to it so that their husbands could join the ranks of the community leaders. This report introduces a convoluted scenario that begs the question of whether these women really wanted FGC, or whether they were complying with the social expectation that community leaders should be married to 'real' women?

\section{4}

\section{Conclusion}

We all know that FGC is perpetuated by social norms and that traditional practices are not static, but informed, reimagined and subsequently reinvented to fulfil social requirements and adapt to emerging extrinsic or intrinsic factors. Interestingly, culture is dynamic and influenced by socio-ecological, historical and structural contingencies that interact with individual and other contextual factors to produce associated meanings and cultural values (Burke et al. 2009).

In this chapter, I have argued that the more FGCS is medically allowed, the more medicalized FGC will take place. It is clear that FGCS and FGC are converging procedures, which complicates the fight against $\mathrm{FGC}$. We can approach this issue in various ways. First, by strengthening the legal and policy frameworks, so that no grey areas remain for the practitioners of both FGC and FGCS to exploit. It is unfair to consider FGC a form of violence - which it is while a very similar 'genuine therapeutic' procedure is not. This will ensure that there is no vilification of one practice over the other since they are very like one another. In addition, the call to ban FGC as a non-therapeutic practice while permitting FGCS as a therapeutic procedure, perpetuates the references to FGC as 'barbaric' (Sheldon and Wilkinson 1998), hence complicating efforts to eradicate it. 
Second, focusing on the programmatic aspects of ending FGC, it is crucial to engage HCP s to champion the prevention of both FGC and FGCS. It is also important to have clear-cut guidance on corrective surgeries associated with FGC complications. In essence, it is in the light of such contextual complexities regarding FGC and FGCS that a focus on tackling social norms alone may not suffice to change behaviour. Instead, interventions require multipronged approaches that target a broader range of factors and that consider historical, political, legal structures and processes as intersecting axes for bodily practices (Burke et al. 2009; Cislaghi and Heise 2019; Esho et al. 2013).

\section{References}

Amref 2020a. The effect of COVID 19 on female genital mutilation/cutting and child early and forced marriage. Amref Health Africa Evidence Brief. https://amref.org/kenya/ wp-content/uploads/sites/2/2020/11/Evidence-Brief.pdf.

Amref 2020b. Community led alternative rite of passage: An effective way to ending $F G M / C$. Policy brief. https://amref.org/kenya/download/amref-community-led -alternative-rite-of-passage-policy-brief/.

Australian Society for Plastic Surgeons. 2015. Female genital cosmetic surgery: A resource for general practitioners and other health professionals. https://plasticsurgery.org.au/female-genital-cosmetic-surgery-a-resource-for-general-practitionersand-other-health-professionals/.

Bhalla, N. 2018. "Kenyan doctor goes to court to legalize female genital mutilation." Reuters, 19 January. https:/www.reuters.com/article/us-kenya-women-FGC/ kenyan-doctor-goes-to-court-to-legalize-female-genital-mutilation-idUSKBNiF8296.

Bramwell, R., C. Morland and A. S. Garden. 2007. "Expectations and experience of labial reduction: A qualitative study." BJOG: An International Journal of Obstetrics and Gynaecology, 114, 12: 1493-1499. DOI: 10.1111/j.1471-0528.2007.01509.x.

Burke, N. J., G. Joseph, R. J. Pasick and J. C. Barker. 20og. "Theorizing social context: Rethinking behavioral theory." Health Education and Behavior, 36, 5 (suppl.): 55S-70S. DOI: 10.1177/1090198109335338.

Chai, M. 2020. "5oo girls suffer the cut in West Pokot." The Star, 16 June. https://www. the-star.co.ke/counties/rift-valley/2020-o6-16-5oo-girls-suffer-the-cut-in-westpokot/.

Cislaghi, B. and L. Heise. 2019. "Using social norms theory for health promotion in low-income countries." Health Promotion International, 34, 3: 616-623. D 0I: 10.1093/ heapro/dayo65.

Doucet, M.-H., C. Pallitto and D. Groleau. 2017. "Understanding the motivations of health-care providers in performing female genital mutilation: An integrative review of the literature." Reproductive Health, 14, 46. DoI: 10.1186/s12978-017-0306-5. 
Esho, T., P. Enzlin and S. van Wolputte. 2013. "Borders of the present: Maasai tradition, modernity, and female identity." In Borderlands and frontiers in Africa, edited by S. van Wolputte, 213-233. Munster: LIT Verlag.

Esho, T., S. Kimani, I. Nyamongo, V. Kimani, S. Muniu, C. Kigondu, P. Ndavi and J. Guyo. 2017. "The 'heat' goes away: Sexual disorders of married women with female genital mutilation/cutting in Kenya." Reproductive Health, 14, 164. DoI: 10.1186/s12978-017O433-z.

Grad F. P. 2002. "The preamble of the constitution of the World Health Organization." Bulletin of the World Health Organisation, 80, 12: 981-984.

Gruenbaum, E. 2015. "Socio-cultural dynamics of female genital cutting: Research findings, gaps, and directions." Culture, Health \& Sexuality, 7, 5: 429-441. Dor: $10.2307 / 4005473$.

KNBS (Kenya National Bureau of Statistics), et al. 2015. "Female genital cutting." In Kenya: Demographic and health survey 2014, 331-343. Nairobi: KNBs. https://dhsprogram.com/pubs/pdf/FR3o8/FR308.pdf.

Liao, L. M. and S. M. Creighton. 2011. "Female genital cosmetic surgery: A new dilemma for GPs." British Journal of General Practice, 61, 582: 7-8. DoI: 10.3399/bjgp11X548893.

Macharia, W. 2013. "Girls taken to hospital after undergoing circumcision." Daily Nation, 4 December. https://nation.africa/kenya/counties/nakuru/girls-taken-tohospital-after-undergoing-circumcision-922422.

National Council for Law Reporting 2011. Prohibition of Female Genital Mutilation Act $N^{\circ} 32$ of 2011. http://kenyalaw.org/kl/fileadmin/pdfdownloads/Acts/ProhibitionofFemaleGenitalMutilationAct_No32of2o11.pdf.

National Council for Law Reporting. 2017. "Constitutional Petition 8 of 2017". http:// kenyalaw.org/caselaw/cases/view/154401.

O’Neill, S., D. Bader, C. Kraus, I. Godin, J. Abdulcadir and S. Alexander. 2020. "Rethinking the anti-FGM zero-tolerance policy: From intellectual concerns to empirical challenges." Current Sexual Health Reports, 12: 266-275. DoI: 10.1007/s11930-02Ooo299-9.

Ostrzenski, A. 2012. "Vaginal rugation rejuvenation (restoration): A new surgical technique for an acquired sensation of wide/smooth vagina." Gynecologic and Obstetric Investigation, 73, 1: 48-52. DOI: 10.1159/ooo329338.

Sheldon S. and S. Wilkinson. 1998. "Female genital mutilation and cosmetic surgery: Regulating non-therapeutic body modification." Bioethics 12, 4: 263-285.

Shell-Duncan, B., R. Naik and C. Feldman-Jacobs. 2016. A state-of-the-art-synthesis of female genital mutilation/cutting: What do we know now? New York: Population Council. https://www.popcouncil.org/uploads/pdfs/SOTA_Synthesis_2016_ FINAL.pdf.

Shell-Duncan, B., A. Moreau, K. Wander and S. Smith. 2018. "The role of older women in contesting norms associated with female genital mutilation/cutting in Senegambia: A factorial focus group analysis." PLoS ONE 13, 7. DOI: 10.1371/journal.pone.0199217. 
UNFPA. 2014. Implementation of the international and regional human rights framework for the elimination of female genital mutilation. New York: United Nations Population Fund.

UNFPA. 2020. Interim technical note impact of the COVID-19 pandemic on family planning and ending gender-based violence, female genital mutilation and child marriage. New York: UNFPA. https://www.unfpa.org/sites/default/files/resource-pdf/COVID19_impact_brief_for_UNFPA_24_April_2020_1.pdf.

UNFPA-UNICEF. 2017. Accelerating change: By the numbers - 2016 annual report of the UNFPA-UNICEF Joint Programme on Female Genital Mutilation/Cutting. New York: UNFPA/United Nations Children's Fund. https://reliefweb.int/report/world/ accelerating-change-numbers-2016-annual-report-unfpa-unicef-joint-programme -female.

UNICEF. 2016. "New statistical report on female genital mutilation shows harmful practice is a global concern." Press release. https://www.unicef.org/media/media_90033 .html.

UNICEF.2O2O.Femalegenitalmutilation:A newgeneration callsfor ending anold practice. New York: UNICEF. https://data.unicef.org/resources/female-genital-mutilation -a-new-generation-calls-for-ending-an-old-practice/.

WHO. 2018. Care of girls and women living with female genital mutilation. A clinical handbook. Geneva: World Health Organization. 